\title{
What is at stake in debates among normative realists?*
}

\author{
Tristram McPherson \\ Virginia Tech \\ tristram@,vt.edu
}

\begin{abstract}
This is the pre-peer reviewed version of the article, the final version of which is forthcoming in Noûs: http://onlinelibrary.wiley.com/journal/10.1111/(ISSN)1468-0068.
\end{abstract}

\begin{abstract}
One class of central debates among normative realists appears to concern whether we should be naturalists or reductionists about the normative. However, metaethical discussion of naturalism and reduction is often inconsistent, murky, or uninformative. This can make it hard to see why commitments relative to these metaphysical categories should matter to normative realists. This paper aims to clarify the nature of these categories, and their significance in debates between normative realists. I develop and defend what I call the joint-carving taxonomy, which builds on David Lewis' notion of elite properties. I argue that this taxonomy is clear and metaphysically interesting, and answers to distinctive taxonomic interests of normative realists. I also suggest that it has important implications for the project of adjudicating debates between normative realists.
\end{abstract}

\section{Introduction}

Athena thinks that torture is wrong. She also takes herself to know a fair bit about what is involved in making this normative judgment. She thinks that her making this judgment does not merely express her attitudes. She thinks that this normative judgment is true, and true because it corresponds to facts that are independent of her own psychology and talk. In short, Athena is considerably clearer and more sophisticated in her opinions about metaethics than most. Nonetheless, she is far from having a worked out metaethical theory.

Suppose that Athena tries to develop such a theory. She might begin by asking: what are the theoretically important distinctions among normative realisms? One prominent answer is: the divisions between non-naturalism, non-reductive naturalism, and reductive naturalism about the normative. This set of categories is given pride of place as an 
organizing idea both in pedagogical texts (Shafer-Landau and Cuneo 2007, 158-60; Miller 2013, Ch.s 8-10), and in what is arguably the most metaphysically sophisticated recent monograph on normative realism (Wedgwood 2007, Part II).

There is a compelling initial motivation for focusing on this set of categories. Normative realism, most of its proponents insist, is a metaphysical thesis. And reduction, monism, and dualism are central ways of organizing views across metaphysics. It is thus natural to suppose that they will also helpfully delineate some of the most metaphysically important options available to the prospective normative realist. However, metaethical discussion of naturalism and reduction has two striking features. First, disagreement about how to understand these categories is both ubiquitous and deep. Second, despite this disagreement, metaethicists often argue for and against naturalism or reduction about the normative without carefully characterizing how they understand them. This circumstance is understandable. Providing a compelling argument for non-naturalistic realism (for example) can seem to be a more worthwhile philosophical goal than painstakingly explaining what such a view consists in. It is tempting to think that clarifying a metaphysical taxonomy is mere logic (or world) chopping, unworthy of serious philosophical attention.

The danger of succumbing to this temptation, however, can be brought out by considering how one might argue against a metaethical view, without carefully characterizing it. The temptation is to argue against some paradigm(s) of the view, and then suggest that your argument generalizes to all instances of such a view. The history of metaethics suggests that this is an accident-prone strategy: we now know that normative naturalism is compatible with the existence of Moorean 'open questions'; that intuitionism is compatible with the rejection of non-naturalism; and that expressivism is compatible with pre-theoretical belief in normative truths, facts, and knowledge (if expressivism's leading contemporary proponents are to be believed). ${ }^{1}$

This suggests that we may be able to make progress in the debates among normative realists by stepping back from the cut-and-thrust, and focusing on carefully examining the metaphysics of reduction and naturalism in metaethics. It is here that we can hope to discover what is at stake in these debates. This promises to permit a clearer reevaluation of the arguments that are allegedly supposed to favor one variant of normative realism over others. 
This paper, then, aims to clarify what is at stake in central fundamental metaphysical debates among normative realists. To keep the project manageable, I set aside the broadly semantic debates between normative relativists, contextualists, invariantists, realist-expressivists, etc., and the structural debates between teleologists and buck-passers, and between response-dependent and response-independent theorists. I also set aside 'meta-metaethical' debates about whether normative realism is best understood as a metaphysical doctrine at all. ${ }^{2}$

'Reduction' and 'naturalism' are plausibly both terms of art. $^{3}$ One might object that this point undermines the interest of my project: if disputes about terms of art are merely verbal, then normative realists should just clearly state their preferred taxonomy, and get on with their substantive arguments. This objection fails because theoretical taxonomies can be dramatically better and worse, in virtue of how useful they are to the theoretical projects they serve. This point in turn directs us to the desiderata that we should use to evaluate candidate taxonomies.

The relevant theoretical project in this case is the metaphysics of the normative. To be useful to this project, accounts of naturalism and reduction should be guided by two central desiderata. First, because of the metaphysical nature of the project, apt characterizations of 'naturalism' and 'reduction' should provide clear and theoretically useful descriptions of metaphysically interesting features. Second, these are central categories used to organize debates between normative realists. They should thus answer to the theoretical interest that self-conscious participants in those debates have in characterizing the metaphysical distinctions between their views.

In this paper, I develop a taxonomy of normative realisms tailored to meet these desiderata, which I call the joint-carving taxonomy. This taxonomy appeals centrally to the idea of elite structure - an idea first developed by David Lewis (1983), and recently given powerful expression by Ted Sider (2012). I first show how the appeal to elite structure permits an illuminating account of naturalism as a metaphysical thesis, which vindicates metaethicists' interest in the question of naturalism $(\S 1)$. This puts me in a position to reject an important alternative interpretation of debates between normative realists, which construes them as purely local debates about the relation between the normative and everything else $(\S 2)$. I then introduce a framework for thinking about the metaphysics of 
reduction and dualism (§3). Finally, I use this framework to develop an illustrative taxonomy of normative realisms ( $\$ 4)$. I show that this taxonomy captures much of what normative realists care about in their intramural debates. I also show that this taxonomy has dialectical bite, suggesting some important lessons for the argumentative strategies that normative realists use in these debates.

\section{Characterizing the natural}

At least since G. E. Moore, the relationship between the normative and the natural has been a central locus of debate between normative realists. ${ }^{4}$ However, there are reasons to worry that this focus is misguided. In this section I address these worries in three ways. I first explain the distinctive interest of the relationship between the normative and the natural to the metaphysics of the normative. I then offer some preliminary clarification of the central issue. However, the core of this section is constructive: I develop a substantive account of the natural, and argue that it vindicates metaethicists' interest in this category.

There are at least three reasons to worry about normative realists' focus on the natural. First, it can appear idiosyncratic. Parallel debates in general metaphysics, and in the philosophy of mind, are most often cast in terms of the physical, not the natural. Second, one might worry that this theoretical focus is an historical accident, a result of the profound influence of Moore's Principia Ethica on the way that metaethical debates are framed. Finally, metaethicists have offered a veritable sea of competing conceptions of the natural, which might raise doubts about whether they are all trying to latch onto a single metaphysically interesting category. Dramatizing the challenge further, Allan Gibbard (2003, Ch. 2) has suggested that Moore's own distinctive concerns are best developed by insisting on a contrast between normative and natural concepts. If true, this would suggest that the continuing metaphysical debate fails to even capture the motivations that initially prompted the contrast.

An initial reply to the first two challenges can be constructed by sketching the contrasting theoretical challenges facing metaethics and the metaphysics of mind. To begin, consider why it makes sense for the philosophy of mind to focus on the relationship between the mental and the physical, rather than the mental and the natural. Part of the reason for this is that the case for the naturalization of the mind is so powerful: psychology 
and cognitive science are arguably already relatively mature sciences. This constrains the plausible metaphysical options in the philosophy of mind. Thus, David Chalmers - a paradigmatic anti-physicalist about the mental - posits nomically robust physicalphenomenal bridge laws (e.g. 1996, 127-9). Chalmers' anti-physicalism stems from the fact that he takes these laws to fail to extend across all metaphysically possible worlds. The assumption of such bridge laws means that even an anti-physicalist like Chalmers embraces a metaphysics of the mental that is friendly to robust scientific investigation of the mind. The upshot of this is that the relationship between the mental and the natural (while intrinsically interesting) is arguably too uncontroversial to sustain a central philosophical debate.

By contrast, there is no well-developed scientific project focused on illuminating the nature of the normative. Further, it is a matter of fierce controversy whether normative properties can be causally efficacious or explanatorily potent, and whether the epistemology of the normative is relevantly continuous with that of science. ${ }^{5}$ Because of this, the question of whether normative properties fit into the scientific picture of reality is live and central in a way that it is not in the philosophy of mind. This is why the natural is an interesting theoretical target for normative realists, while it is not in the philosophy of mind.

This vindication of normative realists' interest in the natural is contingent on rebutting the third worry I introduced above. That worry was that the heterogeneity of extant conceptions of the natural cast doubt on whether there was really an interesting metaphysical category here to be described. Here, I will reply constructively, offering a clear conception of the natural that I take to vindicate the interest normative realists have in this category.

I begin by clarifying one potential source of confusion. This is the idea that the distinction that normative realists care about is a simple dichotomy: natural vs. nonnatural. Despite being intuitive, this idea is potentially misleading. The most prominent tradition of non-naturalists follows Moore, who famously contrasted his view of normative properties with both naturalist and supernaturalist proposals. ${ }^{6}$ Supernaturalism about the normative takes normative properties to be (or to be grounded in) supernatural properties. The most familiar instance is the Divine Command thesis that we can reduce normativity to 
a certain relation to God's will (compare Adams 1999). The Moorean, by contrast, insists that normative properties are metaphysically sui generis: different in kind from the natural properties, the supernatural properties, and, indeed, any other class of properties (ShaferLandau 2003, 55ff; cf. Moore 1903, 39). Figure 1 illustrates the range of possible views just discussed:

Figure 1: a framework of locations for the normative

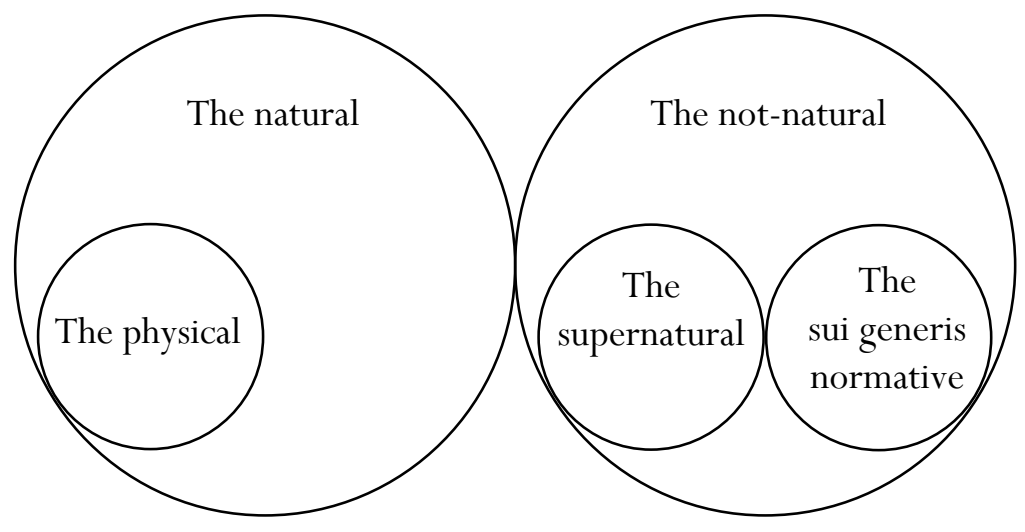

This framework builds in one further plausible constraint on the nature of the natural: however we wind up characterizing it, the natural should be understood as containing the physical as a (possibly improper) subset (compare Kim 2011, 109).

Some of the heterogeneity in metaethical conceptions of the natural can be explained by appeal to this framework. For example, philosophers occasionally use the word 'natural' to describe the complement of the sui-generis non-natural. ${ }^{7}$ If one is solely interested in investigating the prospects for a Moorean-style view, this may be understandable. However, there are strong reasons to reject this characterization of the natural. For example, it courts confusion to use a conception of the natural on which supernatural properties are stipulated to be natural (compare Sturgeon 2009, 63-4).

This approach is also inconsistent with the second desideratum that I introduced above to guide my taxonomic enquiry: that the categories deployed should answer to the core theoretical interests of normative realists. One of those core interests is to evaluate the compatibility of normative realism with a naturalistic worldview, in light of the sort of prima facie challenges to this compatibility sketched on p. 5 above. Supernaturalist 
hypotheses are paradigmatically incompatible with a naturalistic worldview. Consider, for example, the property of being godlike, where this involves standing outside of space and time, but nonetheless having both psychological attributes, and the capacity for being an 'uncaused cause' of events in space and time in ways that violate the laws of nature. ${ }^{8}$ It seems metaphysically possible that this property be instantiated. But the hypothesis that it is actually instantiated is inconsistent with naturalism. The contrast between natural and supernatural properties is thus metaphysically substantive, and tracks a question of central interest to many normative realists. A conception of naturalism that obscures this distinction is therefore a poor way to organize variants of normative realism.

This point about supernatural properties makes trouble for two influential conceptions of the natural. First, one might suggest that the natural properties are just the causally efficacious properties. However, the instantiation of divine causation that violates the laws of nature appears plainly inconsistent with naturalism. Second, perhaps the most recently influential conception of the natural in metaethics is the view that natural properties are those discoverable only through empirical investigation. ${ }^{9}$ The problem with this conception is that it seems possible that the existence of a godlike being could be known only through such investigation. For example, this would be true on a theology that rejected ontological arguments and their ilk, in favor of worldly evidence of the divine.

The example of supernatural properties like being godlike can thus function to highlight the inadequacy of some leading conceptions of the natural in metaethics. It also suggests a way to proceed in developing a positive conception of the natural: to appeal to contrasting paradigms, like the physical and the supernatural. Notice, however, that appeal to these paradigms does not by itself suffice to fix a determinate characterization of the natural. Even if we stipulate that properties can be exhaustively partitioned into two classes $\{$ physical...\} and $\{$ supernatural...\}, this leaves open the question of what principle determines how to fill in the ellipses in these two classes. There are many alternative here; I briefly note two that we should reject. First, on one response-dependent characterization of naturalism, the correct partition would be determined by the groupings that we find intuitive. Second, on one epistemic characterization of naturalism, the ellipsis would be filled in by identifying epistemic contrasts between the physical and supernatural, and 
filling out the classes according to whether they shared the distinctive epistemology of the physical.

Both of these alternatives strike me as unacceptable because they fail to respect the first desideratum that I identified in the introduction: to identify a metaphysically interesting distinction. Consider the response-dependent view: why should our investigations of the fundamental character of reality be organized by certain partitions simply because we take those partitions to be intuitive? That way lies a metaphysics in which up and down are fundamental categories. The epistemic characterization faces a similar worry: the very same epistemology might provide us with access to a metaphysically heterogeneous class of properties. That would make this class epistemically interesting, but not metaphysically significant.

These cases show that we need a principle for filling out our contrast classes $\{$ physical...\} and $\{$ supernatural...\}, that renders the distinction between them metaphysically significant. My approach begins with the thought that in order to be metaphysically significant, this distinction must mark a joint of nature. In what follows, I develop a conception of naturalism that respects this intuitive constraint.

In developing this conception, I follow David Lewis' helpful discussion of the idea of a joint-making property. Lewis called these properties 'elite' or 'sparse' properties. ${ }^{10}$ The contrast is with properties in an 'abundant' sense, on which any predicate that has an extension counts as picking out an actual property. ${ }^{11}$ The framework of elite properties is both powerful and plausible. ${ }^{12}$ Consider an illustrative example. It is plausible that being made of gold is an elite property. Samples of gold all share an interesting physical nature: they are all made almost entirely of atoms that have 79 protons. This seems like it is a joint of reality: a description of the world that failed to mark the distinction between gold and other materials would thereby be impoverished.

I follow Lewis $(1984,227-8)$ in assuming that eliteness is a gradeable phenomenon. So, consider some less elite properties. Having mass and being made of gold are plausibly elite properties, while the disjunctive property having mass or being made of gold seems less elite, in virtue of its disjunctiveness. Or consider the class of things that I find tasty. Facts about the nature of things in this class undeniably help to explain why I find them tasty. However, the similarity that explains why I find them tasty is plausibly much less elite than 
the similarity that unites the samples of gold. One plausible goal for metaphysics is to understand the nature of relatively elite properties, and the relation of salient less-elite properties in terms of the more elite.

With this framework in hand, my characterization of the natural can be sketched as follows. As we have seen, there are paradigm supernatural properties - like being godlike whose instantiation would refute naturalism. Focus next on the positive naturalistic paradigms. There are domains of enquiry that are (a) paradigmatically naturalistic, and (b) paradigms of successful enquiry. I take it that at minimum, large parts of the natural sciences (for example: biology, geology, and physics) fit this description. I make two crucial assumptions about the properties identified by the central well-confirmed theories within those domains:

1. The existential claims made by these theories are not wildly inaccurate. In other words, at least for the most part, these theories have identified actual relatively elite properties.

2. Most of the properties correctly identified and described by those theories partially constitute an elite metaphysical similarity class.

My talk of 'elite similarity' here is of a piece with my talk of elite properties. Such a similarity is not merely something about a class's underlying nature that explains why we group its members together (this is true of the class of things that I find tasty). Rather, it involves its members sharing an underlying elite metaphysical nature (as with the class of gold things).

Why are these assumptions crucial for a discussion of metaphysical naturalism? Suppose that the first assumption were to fail. Then it is deeply unclear that we have a reasonable grip on what we are talking about when we are talking about natural properties. Perhaps we can refer to them. However, if most of what we take to be paradigmatic instances of such properties are non-existent or non-elite, then this class of properties is likely an inappropriate focus for our metaphysical theorizing. Suppose instead that the second assumption were to fail. In this case, the properties that we call 'natural' would not share a deep metaphysical nature; perhaps we only group them together for pragmatic reasons or because of some historical contingency in our enquiry. This again suggests that the category of the natural should not play a central role in our metaphysical theorizing. To be clear, I take skepticism about these two assumptions to be unfounded: I discuss it only 
because it illustrates the significance of the characterization that I offer of natural properties.

I have now introduced two key notions: the idea of an elite similarity class, and the idea that the properties postulated by the paradigmatic natural sciences partially constitute a real similarity class. I need one further distinction before offering my conception of the natural. A property might count as natural for one of two reasons: first, it might count as natural in virtue of being a member of the naturalistic similarity class. Second, a property might count as natural only in virtue of being reducible to properties that are members of the naturalistic similarity class. I take up questions of reduction in the next section. Here, I make the first notion - basic membership - more precise. I characterize a basic natural property as follows:

Basic A basic natural property is a property that is a member of the narrowest real similarity class that is partially constituted by the real properties correctly postulated by paradigmatic natural sciences, and that excludes paradigmatic supernatural properties. ${ }^{13}$

Some will find the schematic nature of this characterization frustrating. After all, it raises an obvious question: what is the real similarity shared by these properties? An account that answered this question would provide a substantive characterization of the natural. For example, someone might propose that what unifies the basic natural properties is that they are all and only those properties whose essences immediately explain laws of nature.

My account is compatible with a range of such substantive characterizations. It is also compatible with epistemic modesty about our ability to give a fully satisfying answer to this question. One can have reasonable confidence that all $F$ s share a deep nature, without being able to tell a convincing story about what precisely that nature is. (Compare the broadly Lockean attitude towards natural kinds.)

I initially suggested that normative realists' interest in naturalism stemmed from the question of whether normative properties fit into the picture of reality provided by the sciences. Let me say a little more about why this question is of central interest to normative realists. First, the paradigmatic natural sciences are themselves paradigms of human explanatory success. Second, the history of the natural sciences is to some extent explanatorily imperialistic: it is not obvious that the natural sciences exclude any theoretical questions from their purview. Indeed, the sciences have accumulated an 
impressive record of explanatory success in their very imperialism, extending robust scientific explanations to the very micro and very macro scales. Ambitiously, these successes might be taken to suggest a kind of optimistic induction: this pattern will continue, and we will (at least in principle) be able to explain all of reality purely in terms of natural properties. More modestly, the attempt to offer a naturalistic account of a domain can reasonably aspire to thereby achieve explanatory success, whatever the fate of naturalism as a global metaphysical thesis.

The conception of the basic natural properties that I have offered fits neatly with these familiar, if controversial, thoughts. This is because it understands the class of basic natural properties as the metaphysically significant pattern suggested by the ontological commitments of our best scientific theories. It thus helps to explain normative realists' theoretical interest in determining whether normative properties are natural. It vindicates the core reason to be attracted to normative naturalism: it promises to fit normative properties into the most robust explanatory framework that we have. It similarly suggests high stakes for debates about non-naturalism. On the one hand, the force of naturalistic imperialism may cast doubt on the existence of normative properties, if we are unable to understand them as natural. ${ }^{14}$ On the other hand, a compelling case for the existence of non-natural normative properties would refute naturalistic imperialism, and hence be of striking general metaphysical interest.

In this section I have sketched a conception of the basic natural properties guided by my two taxonomic desiderata: to characterize a relatively precise metaphysical category, and to show that this category answers to the theoretical interests of the normative realists who discuss it. While the metaphysical conception proposed is both schematic and (inevitably) controversial, I have suggested that it suffices to explain why normative realists should be interested in the 'naturalism question'.

\section{Are debates between normative realists metaphysically local?}

I have argued that the compatibility of the normative with the natural is a live question for normative realists, and I have just sketched a conception of the category basic normative property that begins to regiment that question. However, despite all of this, one might 
wonder whether focus on this category is inappropriate for normative realists. According to what I will call the locality interpretation, one's job as a metaethicist would be done if one had successfully elucidated the relationship between the subject-matter of ethics and the stuff it is someone else's job to worry about. (Perhaps that someone else is a scientist, philosopher of mind, or general metaphysician.) One attraction of this interpretation is that it would permit the normative realist to avoid the vexed debates over the character of the natural discussed in the previous section. More importantly, however, this interpretation might seem to well-describe the distinctive task of the metaethicist.

Consider Mark Schroeder's recent defense of the Humean theory of reasons. Schroeder's central thesis can be summed up in two claims. First, he claims that all normative facts can be reduced to facts about reasons. Second, he claims that facts about reasons can in turn be reduced to facts about desires (2007, Ch. 4). You might think that Schroeder need not care about whether we should be reductive naturalists about desire in order to offer a complete reductive metaethic. This thought resonates with Schroeder's own conception of his project. While Schroeder is typically treated as a reductive naturalist, he has recently replied to such an interpretation of his view by commenting that he finds the term 'naturalism' to be "unhelpful" (forthcoming, §3).

The locality interpretation of the metaethical project faces at least two serious problems, however. First, it ignores the theoretical interest of the question of naturalism, which I have just emphasized. Schroeder's own view arguably obscures this point, because it may seem easy to feel confident in the naturalistic credentials of desires. If this confidence is warranted, then Schroeder can safely ignore worries about how exactly to characterize naturalism, in virtue of the distinctive commitments of his view. To see this point, contrast Schroeder's account with a theory that purported to reduce the normative to a class of properties $\mathrm{C}$, whose status with respect to naturalism was radically unclear. Such a view would obviously be informative. However, it might also be accused of failing to discharge the explanatory ambitions that are at the heart of metaethical enquiry. It is easy to see why such an account would better address those ambitions, if it went on to vindicate or debunk the naturalistic credentials of the C-properties.

The second problem facing the locality interpretation is that some influential normative realists, like Richard Boyd (1997), simply eschew the local strategy. On Boyd's 
account, there are robust (but defeasible) causal mechanisms that tend to unify a set of properties, which together constitute moral goodness. Goodness thus constitutes an empirically discoverable and nomically robust natural kind (1997, esp. 116-18 and 122). Boyd (1997) treats the details of his concrete proposal - 'homeostatic consequentialism' more-or-less as an example. His broader metaphysical thesis is that normative properties are structurally analogous to high-level biological properties like being a healthy organism (1997, 118). Similarly, he defends an epistemology of the normative that is just a special case of scientific enquiry (1997, 124-226). These arguments suggest that the normative, whatever its exact character, will very likely turn out to be naturalistic. As Boyd's theory illustrates, it may be attractive to defend the naturalistic credentials of the normative directly, rather than by appeal to some alleged local reduction of the normative. The locality interpretation of the metaethical project fails to capture the fact that this is an important and potentially illuminating metaethical strategy.

A related point applies to the Moorean non-naturalist. As I noted in $\S 1$, the Moorean insists on a kind of local dualism: the normative is claimed to be different from everything else. However, the prima facie case for global naturalism (the thesis that everything actual is natural) can be one of the most significant dialectical barriers to the plausibility of Moorean non-naturalism. Because of this, it can be dialectically crucial for the Moorean to argue against global naturalism, for example via appeal to non-normative companions in guilt, in the course of arguing for their more demanding thesis.

Together, these points suggest that a taxonomy of normative realisms that ignored the significance of naturalism would be problematically idiosyncratic, failing to capture crucial metaphysical structure in metaethical debates. The locality idea is thus best understood as reflecting a kind of strategy that some normative realists will find appealing, rather than as a helpful way of characterizing the realists' central metaphysical options.

\section{Reduction, naturalism, and dualism}

The preceding two sections have developed a distinctive conception of natural properties, and defended the metaethical significance of enquiring about the relationship between the normative and the natural. This section proceeds in two stages. First, it identifies three 
metaphysically interesting structural relations that normative properties might bear to the naturalistic similarity class: strong supervenience, minimal duplicate preservation, and elite derivation. With these relations in hand, I consider how we should understand theses of reduction, naturalism, and dualism with respect to the normative.

To begin, suppose that the properties being negatively charged and being ionically bonded are both basic natural properties. Consider the disjunctive property being negatively charged or being ionically bonded. Suppose that this is not a basic natural property. (This might be true because the disjunctiveness of this property entails that it is not elite enough to constitute one of the natural joints.) Nonetheless, the disjunctive property bears an interesting relation to the basic natural properties: its distribution strongly metaphysically supervenes on the distribution of the basic natural properties. For a property A to strongly metaphysically supervene on the basic natural properties B is for it to be the case that for any metaphysically possible worlds $\mathrm{w} 1$ and $\mathrm{w} 2$, and any individuals $\mathrm{x}$ in $\mathrm{w} 1$ and $\mathrm{y}$ in $\mathrm{w} 2$, if $\mathrm{x}$ any $\mathrm{y}$ instantiate the same B-properties, then they instantiate the same A-properties (compare Kim's principle Strong Covariance I at 1993, 141). This is true, because the disjunctive property strongly supervenes on the distribution of the disjuncts, which are themselves stipulated to be basic natural properties: across every pair of metaphysically possible worlds, every pair of individuals that is identical with respect to instantiation of the disjuncts is identical with respect to instantiation of the disjunctive property.

Next consider the disjunctive property being negatively charged or being godlike. Stipulate that being negatively charged is a basic natural property, that being godlike is not a natural property, and that this disjunctive property is not a basic natural property. Unlike the previous example, this disjunctive property does not strongly supervene on the basic natural properties. This is because there are pairs of metaphysically possible worlds with identical distributions of basic natural properties which differ in their distribution of godlike beings, and hence in their distribution of this disjunctive property. There is nonetheless an interesting modal relation between the basic natural properties and this property. Call a possible world a minimal naturalistic duplicate of the actual world if it is constructed by replicating all of the actual patterns of instantiation of the basic natural properties, and then stopping. Assuming that there are no actual godlike beings, every such 
minimal natural duplicate world will, ipso facto, duplicate the actual distribution of the disjunctive property.

The third sort of relation I want to identify appeals to the framework of elite properties introduced in the previous section. To repeat the core motivation for this approach: the project of metaphysics is to reveal the structure of the actual and possible. I suggested above that elite properties are properties that partially constitute that structure. We can extend this idea, by introducing the idea of an elite property-forming function. For example, consider a volume of a gas under non-extreme conditions. The average function of the kinetic energy levels of the gas's constituent molecules arguably defines an elite property of the volume of gas: its level of heat. By contrast, many other functions of those kinetic energy levels fail to define elite properties. (For example, consider the mathematical product of the energy levels of some arbitrarily chosen subset of those molecules). On this view, certain constitution functions - like the average function of the energy levels just mentioned - are themselves elite. When the conditions of these functions are satisfied, (1) this entails the instantiation of a further elite property, and (2) the function itself provides an informative real definition of that property. This view suggests an attractive conception of asymmetrical structure among the elite properties. ${ }^{15}$

This discussion puts us in a position to characterize four hypotheses about the relation between the normative and the natural:

Membership Every elite normative property is a member of the basic naturalistic similarity class, as characterized in $§ 1$.

Elite $\quad$ The real definition of every elite normative property is provided by an elite property-forming function of the basic natural properties.

Supervenience The pattern of instantiation of normative properties is metaphysically entailed by the pattern of instantiation of the basic natural properties.

Duplication Every minimal basic naturalistic duplicate of the actual world is a normative duplicate of the actual world.

Two preliminary notes about these hypotheses. First, Membership and Elite make claims about all elite normative properties. This is to allow that there might be properties in Lewis' 'abundant' sense that qualify as normative because (for example) their real definitions are massively complex disjunctions of elite normative properties. Second, the four hypotheses are ordered by strength. If we take identity to be a (trivial) elite propertyforming function, then Membership entails Elite. Real definitional constructability will 
entail strong supervenience, so Elite entails Supervenience. And Supervenience entails Duplication as a trivial consequence.

Among these four relations, Supervenience is especially salient, because it is common to claim that the normative supervenes on the natural. However, a number of recent commentators have suggested that there are important reasons to doubt this claim (van Roojen 1996, 79, Sturgeon 2009, 63, McPherson 2012, 212; cf. also Brink 1989, 158-9). One reason for this doubt is that there seem to be possible normatively significant relations that involve supernatural beings. For example, it seems metaphysically possible that one supernatural being wrongly tortures another just for fun. The fact that possible supernatural entities can stand in normative relations might seem to suggest that the supervenience of the normative on the natural must fail.

There are two reasons why this inference might be too quick. First, the characterization of natural properties given in $\S 1$ (and many of its competitors) does not rule out the possibility of beings with some supernatural properties - such as being godlike - also possessing natural properties. ${ }^{16}$ For example, godlike beings are stipulated to have psychological properties, and psychological properties might plausibly turn out to count as members of the naturalistic similarity class. Second, some properties appear not to bear on whether a world is wholly natural. For example, consider the property of being selfidentical. The fact that every possible object is self-identical seems to be irrelevant to whether those objects count as wholly natural, supernatural, etc. Call such properties category-neutral properties. One might thus hope to argue that where supernatural beings stand in normative relations, this is wholly in virtue of their natural or category-neutral properties. This suggests that it may be possible to defend a variant of Supervenience that claims that the normative properties supervene on the basic natural and category-neutral properties. Doing so, however, would require some very delicate argumentation concerning the categorization of the properties of supernatural beings whose actions have normative properties.

With these four hypotheses in hand, I turn to consider how normative realists should understand naturalism and reduction, beginning with the latter. One challenge facing theorists of reduction is that 'reduction' has meant many different things in recent 
philosophy (compare Stoljar 2010, 161-2). This can make it hard to get a grip on what is at stake in claims about reduction.

Some controversies about reduction are hard to see as substantive. One example concerns what we should say about the basic natural properties. A common view of reduction suggests that reductions state property identities (compare Kim 2008, 100). This suggests that to show that every $\mathrm{F}$ is among the basic Gs is to reduce the Fs to the Gs. However, this has intuitively awkward consequences: it implies, for example, that the microphysical reduces to the physical. This might prompt us to accept the alternative view: that for a property to reduce to the natural is, ipso facto, for it to be natural, but not a basic natural property. This suggests that we should be non-reductive naturalists about the basic natural properties. On the other hand, that invites confusion, as non-reductive physicalism is perhaps most often understood as holding of properties that satisfy something like Duplication, without being basically physical. Neither of these considerations appears decisive. So this is a case where one should simply be clear about which way one uses the word 'reduction'. Here, I will treat being identical to one of the basic natural properties i.e. satisfying Membership - as entailing non-reductive naturalism, out of respect for the intuitive oddity of the alternative, just mentioned. However, I take this taxonomic choice to be relatively arbitrary.

Other taxonomic disputes are more substantive, and can be adjudicated by appeal to the desiderata introduced at the beginning of the paper. For example, while Richard Boyd and the other 'Cornell realists' are typically treated as the metaethical paradigms of non-reductive naturalism, they characterize themselves this way only relative to a conception of reduction that they reject. This is, roughly, a Nagelian conception of reduction as a relation between theories, rather than property-types (cf. Nagel 1961). Boyd says that this 'analysis' of reduction is “...entirely without justification from the realistic and naturalistic perspective we are considering" (1997, 115). This complaints reflect a version of the first desideratum that I introduced at the beginning of the paper: an account of reduction should characterize a significant metaphysical category. A conception of reduction that takes theories or concepts to be its relata (like Nagel's) fails this desideratum. ${ }^{17}$

On the alternative conception that Boyd endorses, for objects and forces (e.g.) to reduce to the physical just is for them to be composed of physical objects and forces. (1997, 
114-5). This proposal illustrates a further difficulty with metaethical discussions of reduction: they are commonly extremely vague. If 'composition' as used by Boyd is interpreted as picking out a joint-carving relation, something like Elite will be required for the reduction of the normative. If 'composition' is instead interpreted expansively, something like Supervenience will be sufficient for reduction. This unclarity is crucial, because Supervenience and Elite are important competing accounts of reduction. ${ }^{18}$

In the philosophy of mind, it is not uncommon to suggest that something like Supervenience is necessary and sufficient for reduction. ${ }^{19}$ David Chalmers and Frank Jackson argue that the supervenience relation must be conceptually necessary to entail reduction (2001; cf also Jackson 1998, $57 \mathrm{ff}$ and Chalmers 1996, 161). Chalmers categorizes a metaphysical but not conceptual supervenience relation as sufficient for nonreductive materialism $(1996,162)$. Because the Chalmers and Jackson proposal characterizes reduction in terms of conceptual connection, their proposal (like Nagel's) violates the constraint that reduction should constitute an interesting metaphysical category.

The idea that reduction amounts to Supervenience does not face this problem: Supervenience is a clear and interesting metaphysical relation. However, it runs directly into the second desideratum that I mentioned at the outset: that metaethical taxonomy should answer to the theoretical interests of normative realists. The problem is that almost all normative realists - including non-naturalistic realists from Moore onward - have endorsed the supervenience of the normative on the natural. ${ }^{20}$ Modulo the complications mentioned on p. 16 above, the Supervenience criterion of reduction thus risks categorizing all normative realists as reductive naturalists, thereby obscuring the radical metaphysical contrasts between these views. This is a disastrous result for any taxonomy that aims to capture what is at stake in metaphysical debates between normative realists.

Supervenience is an extremely strong modal relation between the normative and the basic natural properties. The basic problem facing the Supervenience criterion of reduction is that almost all normative realists seem prepared to accept such strong modal links between the normative and the natural. This suggests that in order to make taxonomic progress, we should consider whether we can characterize reduction in terms of a relation that is not characterized in modal terms. 
For this reason I now turn to Elite, which is a non-modally characterized relation. The idea that reduction involves a relation like Elite is less common. However, Mark Schroeder (2007, Ch. 4) and Gideon Rosen $(2010, \S 10)$ defend 'real definition' views of reduction. Although they do not explicitly locate their views within a framework of elite properties, they will need something to do the work of elite derivative property forming relations, on pain of permitting any arbitrary function of properties to count as the real definition of a property.

On the sort of characterization that I have in mind, if the real definition of an elite normative property is given by an elite property-forming function that takes only basic natural properties as arguments, then that elite normative property reduces to the natural. The core idea is this: real definitions tell you what it is to be a certain property. And a plausible articulation of the basic idea of reduction is that reduction tells you that what it is to be the reduced property is just to be an elite function of the reducing properties.

This characterization fulfills the two desiderata I have set on taxonomies. First, on a conception of metaphysics that takes the joints of nature seriously, elite properties and functions are exactly the materials that we should advert to when doing metaphysics. Second, this characterization avoids collapsing substantive debates between normative realists. For example, on this taxonomy, the Moorean non-naturalist can intelligibly insist that, even if the normative properties strongly supervene on the natural properties, this does not entail reduction, because the real definition of normative properties is not a function of the natural properties. For this reason, I take the Elite conception of reduction to be the most helpful one for normative realists to deploy in their theorizing.

I now turn from considering reduction to considering what is required for naturalism to be true of the normative. I begin by considering a conception that takes Duplication to suffice for naturalism. It is common to assert that the analogue of Duplication suffices for the truth of physicalism. ${ }^{21}$ This might suggest that Duplication should likewise suffice for naturalism. The core idea behind this conception can be illustrated by considering one of the toy disjunctive properties introduced above: being negatively charged or being godlike. The disjunctive property is itself presumably not a natural property (its real definition ineliminably involves a supernatural property). However, assuming that the actual world contains no godlike beings, the pattern of instantiation of 
the disjunctive property in the actual world does not require that we posit that anything 'spooky' actually exists. Rather, this pattern of instantiation is entailed by the pattern of actual instantiation of the basic natural properties. Further, Duplication is strong enough to rule out some salient dualist hypotheses. For example, it rules out the possibility of what we might call 'normative zombie worlds': worlds that are normatively empty despite duplicating the actual world's pattern of instantiation of basic natural properties. (Compare the influential argument against physicalism in Chalmers 1996.)

The Duplication conception of monism is most plausible given substantive assumptions about what sorts of properties could bear this relation to the physical or natural. And these assumptions are highly controversial in metaethics. Our disjunctive property is one example of a seemingly naturalistically harmless Duplication-respecting property. The functional role property, which looms large in the philosophy of mind, is another. Both of these examples may appear harmless from a naturalistic point of view. However, as we have seen, the situation is very different in metaethics. Here, the paradigm dualist is the Moorean, who insists that normative properties are sui generis non-natural properties. As we have seen, Mooreans tend to insist that normative properties are linked to the natural properties in ways that satisfy Supervenience, and hence Duplication. Short of a case that the Moorean's commitments are incoherent, this makes Duplication as a criterion for naturalism especially inapt in the context of debates between normative realists. The same point applies to Supervenience characterizations of naturalism. As with reduction, the Moorean in effect renders problematic any purely modal characterization of naturalism.

Satisfying Membership or Elite would show that normative properties are among the joints of nature. However, not all ways of metaphysically locating a class of properties need have this character. Consider again of the group of things that I happen to find tasty. It is not particularly plausible that this grouping constitutes an elite property: this grouping looks like a hypostatization of potentially idiosyncratic facts about my tastes. One kind of eliminativist thinks that this warrants eliminating the predicate 'tasty' - and other predicates that name similar non-elite properties - from our metaphysically serious discourse. ${ }^{22}$

To others, this might seem unnecessarily stingy. We might want metaphysics to tell us not just about the joints of nature, but also about how the abundant properties that 
we happen to care about relate to the elite structure. This might inspire the view that if the pattern of instantiation of a non-elite property F satisfies Duplication, then the instantiation of $\mathrm{F}$ is compatible with naturalism. The example of Moorean non-naturalism again shows us that this cannot be quite right: imagine a property whose real definition is a highly gerrymandered function of Moorean elite properties. Again, to understand why this property is not a natural property, we need to appeal to a hyperintensional relation. The plausible thought in the neighborhood is that: the instantiation of every property whose real definition is a (non-elite) function ${ }^{23}$ of only basic natural properties and categoryneutral properties is compatible with naturalism. What we might call a deflationary ${ }^{24}$ naturalistic normative realist has this view of the normative.

What I will call the joint-carving normative realist, by contrast, thinks that normative properties constitute metaphysically significant joints of reality. One attraction of joint-carving normative realism stems from the fact that only elite properties - and not any old gerrymandered carving of reality - pull their explanatory weight. This is important, because a normative realist might hope to provide a vindicating metaphysical explanation of the seemingly distinctive normativity of moral and practical concepts. For example, Mooreans are typically committed to the idea that the distinctiveness of normative concepts stems from the fact that they predicate sui generis normative properties. The reductionist can also hope to provide an explanation of what makes moral and practical concepts distinctively normative. For example, Schroeder's reduction of normative properties, if successful, would suggest that being normative is an interestingly unified psychological phenomenon.

In this section I first introduced a series of metaphysical relations: Membership, Elite, Supervenience, and Duplication. I then used them to explore alternative conceptions of naturalism and reduction that should be of interest to normative realists. The next section puts this material to work in stating a taxonomy for normative realisms.

\section{What is at stake in debates between normative realists}

This section sets out some consequences of the discussion thus far. I begin by concisely sketching the taxonomy suggested by the arguments of the previous discussion. Because of 
the central role that a joint-carving approach to metaphysics plays in this taxonomy, I call it the joint-carving taxonomy. I then use this taxonomy to locate what is at stake in central metaethical debates over naturalism and reduction. Finally, I discuss the broader significance and limitations of the argument of this paper.

The joint-carving taxonomy builds on the points made thus far. To begin, consider some variants of naturalism:

Reductive Naturalism

Non-reductive Naturalism

Deflationary Naturalism
There are actual elite normative properties, and the real definition of every elite normative property is an elite (non-identity) function of only natural properties. ${ }^{25}$

There are actual elite normative properties that are members of the naturalistic similarity class. All elite normative properties are either members of this class, or satisfy Reductive Naturalism.

There are no elite normative properties, only abundant normative properties. The real definition of each normative property is a function of basic natural and category-neutral properties.

These characterizations summarize the discussion of the previous sections. As I noted in the previous section, my characterization of Non-reductive Naturalism here is somewhat stipulative: one could instead take this characterization to be another way for reductive naturalism to be true.

Recall from $\S 1$ the importance of distinguishing Moorean non-naturalism from a broader denial of naturalism about the normative. Both can be helpfully characterized within the joint-carving framework. Broad Non-naturalism can be characterized negatively: it just combines the claim that there are normative properties with the denial of Reductive Naturalism, Non-reductive Naturalism, and Deflationary Naturalism. The Moorean wants something stronger than this: she claims that normative properties are metaphysically 'sui generis'. ${ }^{26}$ This claim can be sharpened by understanding it, like the characterization of the natural, as a claim about an elite similarity classes. So construed, the Moorean conception of non-naturalism is as follows:

Moorean Non-naturalism There are actual elite normative properties and the class of normative properties is a distinct metaphysical similarity class: (a) normative properties share an elite similarity shared by no other properties, and (b) normative properties do not share the elite similarities that characterize the natural or supernatural. 
Together, these criteria constitute the joint-carving taxonomy that I advocate. In the previous three sections of this paper, I have argued that the elements from which this taxonomy has been constructed satisfy the two desiderata that I identified at the beginning of the paper: that such a taxonomy should be constructed out of significant metaphysical categories, and that these categories should be responsive to normative realists' theoretical interests. I take that argument to be sufficient to provisionally justify adoption of the jointcarving taxonomy. However, it is natural to wonder whether this taxonomy can shed light on how to make progress in adjudicating the substantive debates between normative realists. I cannot hope to adequately defend the claim that it does, in this paper. However, I will briefly sketch examples of two sorts of implications: three questions in general metaphysics that this taxonomy makes especially pressing for normative realists, and three challenges this taxonomy poses to influential metaethical arguments.

The taxonomy that I have offered suggests that resolving certain questions in general metaphysics is especially crucial for adjudicating debates between normative realists. An obvious example arises from the fact that the conception of naturalism that I have offered here is less substantively informative than one would like. Determining a more substantive characterization of the natural that answers to this schema could have very helpful clarifying implications for debates between normative realists.

Unlike supervenience conceptions of reduction, the joint-carving taxonomy does not define away the possibility of the Moorean's distinctive commitment to dualism coupled with modal inseparability. Instead, it permits a clear framing of the crucial challenge facing the Moorean here. It is often said that the normative realist has a problem 'explaining the supervenience of the normative' (the locus classicus of this challenge is Blackburn 1993, Essay 6). However, it is often somewhat unclear what exactly this challenge comes to. Indeed, for the reductive naturalist, it is not clear that this is a problem at all (Dreier 1992).

The joint-carving taxonomy allows us to isolate one central challenge in this vicinity. We saw in the previous section that it is not clear that the Moorean needs to accept the supervenience of the normative on the natural. However, almost all Mooreans do accept the supervenience of the normative on the non-normative. Together with their insistence on the distinctness of normative properties, this commits the Moorean to a 
necessary connection between distinct properties. Many philosophers think that such connections are impossible. This assumption is reflected in the suggestion discussed above that strong supervenience might suffice for reduction. Philosophers tend to think this because they accept a substantive ${ }^{27}$ metaphysical principle, which is often called 'Hume's Dictum': the claim that there can be no necessary connections between 'distinct existences'. The fact that the conception of non-naturalism that I offer permits the nonnaturalist to state her view does not entail that it lets her off of the hook on this question. Rather, it clarifies the metaethical significance of a central question in pure metaphysics: can we ever reject Hume's Dictum? Are there more modest theses in the vicinity of Hume's Dictum that are more compelling as constraints on our metaphysical theorizing? ${ }^{28}$ This seems like a crucial part of determining what sort of burden the supervenience of the normative poses to the Moorean.

The joint-carving taxonomy also revealed a neglected challenge for the normative naturalist. The three species of normative naturalism that I have sketched require the strong supervenience of the normative. However, as I explained in the previous section, the moral significance of the acts of possible supernatural beings challenges the defensibility of this presupposition. Adjudicating this challenge requires assessing delicate metaphysical questions concerning the possession of natural and category-neutral properties by supernatural entities. If the naturalist fails to vindicate Supervenience, and the Moorean fails to debunk Hume's Dictum (both of which seem quite possible), the results would be dramatic. Broad Non-naturalism, a metaethical view that is barely noticed in the literature, could turn out to be the only defensible form of normative realism.

Next, I want to briefly sketch three challenges that the joint-carving taxonomy poses to influential arguments in metaethics. Following Harman (1977), one of the central challenges that is taken to face naturalistic normative realism is to vindicate the explanatory efficacy of normative properties. However, the joint-carving taxonomy suggests that the force of this demand will be quite different depending upon whether we are elite or deflationary naturalists. One might well expect that if there are normative joints of nature, these would be capable of doing significant explanatory work. By contrast, if Deflationary Naturalism were true, it would be no surprise that normative properties were explanatorily weak; compare the limited explanatory power of the tasty. 
These points about Broad Non-naturalism and Deflationary Naturalism illustrate one of the signal virtues of attention to taxonomy. One of the central avenues of progress in metaethics over the past decades has been the investigation of important theoretical options that have tended to be obscured by previously dominant characterizations of the options: think of 'synthetic' versions of naturalistic realism, of 'quasi-realism', and of 'hybrid expressivisms'. ${ }^{29}$ The joint-carving taxonomy illuminates the status of Deflationary Naturalism and Broad Non-naturalism, as possible views which should be objects of serious investigation.

Mark Schroeder's (2007) is one of the most powerful arguments for a reductive normative realism yet developed. However, the joint-carving taxonomy helps to reveal an important disconnect between the basic form of his argumentative strategy, and the (plausible) conception of reduction that he adopts. Simplifying greatly, Schroeder's basic strategy is to (i) identify a state (roughly: desire) that appears correlated with having reasons in many cases, (ii) argue that the core normative kind are reasons, so that a reduction of reasons will allow one to reduce all of the normative, and then (iii) to argue inventively that the appearance that a reduction of facts about reasons to facts about desire would generate what are intuitively too few or too many reasons can be finessed (2007, Chs. 5 6). If one accepted a supervenience criterion of reduction, this would be a paradigmatically suitable reductive strategy, for it would supportthe necessary coextensiveness of reasons and desires. However, all Schroeder says to motivate the idea that we should think that this underwrites a reductive relation between reasons and desires, rather than simply a modal relation, is that reduction, if true, would explain the modal relation $(2007,71)$. This makes close to no progress in explaining why someone initially sympathetic to Moorean Non-naturalism (for example) should be tempted by Schroeder's reductive view.

On the other hand, consider one of the most inventive recent defenses of Moorean non-naturalism: David Enoch's (2011). A crucial lynchpin of Enoch's argument is the intuitive claim that the normative and the natural are "just too different" for naturalism to be true. This claim plays a crucial role in Enoch's argument. However, the joint-carving taxonomy suggests that this claim is a weak argumentative resource. As the taxonomy makes clear, Moorean non-naturalism is a claim about the real essence of normative properties, the irreducibility of these properties, and the dissimilarity of these properties 
from every other possible kind of property. This is a very complex theoretical claim that crucially involves deploying at least two highly vexed terms of art (reduction and real similarity). Taking an intuition to have significant probative force on this sort of matter seems to me to require postulating that we have a truly extraordinary capacity for insight into reality in this case, and raises questions about why we lack such insight in other seemingly a priori domains. Why, for example, cannot I just see whether numbers are sets? This problem is especially intense when we consider the obvious debunking explanation: that these intuitions are simply tracking differences between normative concepts and other concepts that we possess.

In closing, it is worth emphasizing that I put forward the joint-carving taxonomy in a tentative spirit. This taxonomy is highly controversial: most saliently, it appeals heavily to a conception of metaphysics on which elite properties loom large, and some philosophers profess to find the very idea of such properties unintelligible. Competing accounts might appeal to essences or grounding, or, in case all of that is much too much, the now-standard diet of modal concepts. Debates about the legitimacy of various pieces of metaphysical ideology entail that taxonomy will itself inevitably be a controversial matter: detractors of some piece of ideology will cry "unintelligible!" or "mysterious!", while proponents will say that certain distinctions simply cannot be properly made without it.

My broadest goals in this paper are twofold. First, I want to show by example why it is worth carefully developing a taxonomy for these debates. I find the taxonomy that I have offered attractive, and it thus seems to me to put normative realists in a position to make substantial headway on questions where there otherwise threatens to be more heat than light. Second, however, I am interested in encouraging more active debate among normative realists about these very taxonomic questions. I have suggested two desiderata that constrain the candidates in that debate: appeal to clear and central metaphysical categories, and theoretical utility for metaethical debate. If others can improve on my illustrative taxonomy relative to these desiderata, I will be delighted - and the Athenas of the world will perhaps no longer find the field quite so baffling.

\footnotetext{
* I am indebted to Laura and Francois Schroeter, Derek Baker, Gideon Rosen, David Plunkett, Colin Marshall, Lok-Chi Chan, Billy Dunaway, Stephen Donaho, Jamie Dreier, an anonymous referee for Noûs, and to audiences at the Minnesota Philosophical Society, the Central APA, and the Australasian Association of Philosophy for helpful discussion of ideas that went into this paper.
} 
${ }^{1}$ Careful non-naturalists like Dancy 2006, 132 and Enoch 2011, 100 n.1, are prepared to grant that open questions alone do not help against naturalism. Audi 1997 develops a version of intuitionism in moral epistemology that is separable from the non-epistemological features usually associated with the doctrine. And Blackburn 1993 and Gibbard 2003 offer 'quasi-realist' versions of expressivism that aim to show expressivism to be compatible with ordinary talk of ethical truth, facts, and knowledge.

${ }^{2}$ For quietist skepticism of the idea of normative realism as a metaphysical doctrine, see e.g. Dworkin 1996, Scanlon 1998, 55-64 and 2003, Kramer 2009, and Parfit 2011, §113. For critical discussion see McPherson 2011. Also relevant here is the quasi-realist program, e.g. Blackburn 1993, Gibbard 2003.

3 Oddie pithily states the issue to be addressed: “'Reduction' is, somewhat paradoxically, both a term of art and a hotly contested notion" $(2005,144)$.

${ }^{4}$ Among many others, see Moore 1903, Smith 1994, Boyd 1997, Railton 1997, Shafer-Landau 2003, Huemer 2005, Wedgwood 2007, and Enoch 2011.

${ }^{5}$ The locus classicus of the explanatory challenge is Harman 1977, Ch. 1. For a survey of some of the vast literature on moral explanation and causation that resulted, see Majors 2007.

${ }^{6}$ Moore describes the 'metaphysical' (i.e. supernaturalist) ethicist as purporting to offer truths about 'nonnatural existents' (1903: 112). However, Moore thinks that the naturalistic fallacy applies as much to such proposals as it does to naturalistic accounts of morality $(1903,39)$.

${ }^{7}$ For some examples, see Sturgeon 2009, 63n.24. Wedgwood's characterization of naturalism $(2007,145)$ is a sophisticated variant on this theme.

${ }^{8}$ I take being godlike to be a clear case of a supernatural property. Other imagined properties and objects that we would perhaps casually describe as supernatural might better be described as exotic naturalistic possibilities. For example, consider the ghosts imagined in Ghostbusters movie. These look like they might be unusual and understudied parts of (a fictional) natural reality. I set aside the interesting and substantive question: under what conditions would things deserving the names 'magic', 'ghosts', 'gods', etc, nonetheless count as natural, and under what conditions would they count as supernatural? Thanks to Jamie Dreier for discussion of this issue.

${ }^{9}$ Consider three leading examples of views of roughly this type. Railton says that "A substantive naturalist advances a philosophical account of a domain... that provides an interpretation of its central concepts in terms amenable to empirical enquiry" $(1989,156)$. Shafer-Landau characterizes natural sciences as domains whose fundamental principles are only discoverable a posteriori (2003, 61). Presumably, on this view, a natural property will be one discoverable by an idealized natural science. Michael Smith suggests that natural properties are properties that could feature in an 'empirical regularity' (2004, 212). Presumably, an empirical regularity is one that is discoverable through empirical investigation.

${ }^{10}$ Lewis more often talks calls elite properties 'natural' properties. However, as he notes at 1986, 60n.44, this can be misleading. It is especially misleading in our context, since there are likely possible elite properties (e.g. supernatural properties) that are not natural in the sense I am discussing here. I will thus stick to the less misleading term 'elite'.

${ }^{11}$ Throughout, I simply assume a non-deflationary, metaphysical view about property talk (contrast the quasirealist program, and Quinean deflationism). What is important, though, is the idea that reality has elite structure that cannot be exhaustively characterized in modal terms. If someone found a way to represent this structure without talk of elite properties, I suspect that everything I want to say could be translated into their favored jargon.

${ }^{12}$ Sider 2012 has done important work illuminating the sort of work that a conception of metaphysics which puts elite structure at its center can do. However, it is important to emphasize that even if one rejects Sider's sweeping claim that "Metaphysics, at bottom, is about the fundamental [elite] structure of reality" $(2012,1)$, one can take elite structure to be both real and of profound metaphysical importance.

${ }^{13}$ As I noted above, eliteness is a matter of degree. One might wonder: how elite a distinctive similarity must our paradigms share? Suppose, for example, that the most elite similarity shared by the paradigms is just not that elite: then we seem to have a borderline case of assumption (2) being satisfied. The right thing to say in this case, it seems to me, is that naturalism is a less interesting metaphysical category than we thought.

However, suppose next that this is still among the most elite classifications that we know how to make: then it is still of considerable interest. Thanks to Billy Dunaway and Colin Marshall for discussion of this issue. 
${ }^{14}$ Thus, one core strategy for defending error theory about the normative is to suggest that we are committed to the non-natural character of normative properties, but that global naturalism shows that there is nothing like that. I take this to be one strand of Mackie's case for moral error theory (1977, Ch. 1).

${ }^{15}$ This suggestion marks a contrast with Lewis' own discussion of eliteness. Lewis finds it plausible that all of the actual perfectly elite properties are fundamental physical properties. Lewis also suggests that the degree of eligibility of non-fundamental properties is a matter of the 'length of definition' of those properties in fundamental physical terms $(1984,228)$. This seems to suggest that all simple logical functions of fundamental properties dilute the eliteness of the resulting properties equally. The fact that many scientific kinds - for example cell - appear highly elite despite being related to the fundamental microphysical properties in only fantastically logically complex ways strikes me as counting decisively against Lewis' suggestion (see Hawthorne 2006, 206 for a similar point).

${ }^{16}$ Sturgeon considers and rejects this possibility in 2009, 64-66.

17 Boyd's concern (attributed to him by Sturgeon 1988, 240) is exactly that on a semantic view of theories, metaphysically irrelevant facts about the expressive powers of our language could determine whether reduction holds. For another withering dismissal of Nagel's conception of reduction, see Kim 2008, §II.

18 The same unclarity afflicts Harman's claim that there is a reduction when facts of one sort can be constructed out of facts of the second $(1977,13)$. We are given no grasp on the distinctive nature of the relevant construction relation.

${ }^{19}$ See for example Kim 1993, $151 \mathrm{ff}$. Kim 1993, 152 suggests that supervenience across the nomologically possible worlds is sufficient for reduction. However, by 2008, 99, he explicitly rejects this idea.

${ }^{20}$ For example, see Moore 1998, esp. 55-7, Shafer-Landau 2003, 78, and FitzPatrick 2010, §10. Rosen 2010, §13 helpfully dubs such alleged metaphysically fundamental modal ties "Moorean connections."

${ }^{21}$ For example, Bennett 2008, 284 and Braddon-Mitchell and Jackson 2007, 29 endorse duplication theses as a criterion for physicalism. See Stoljar 2010, Chs. 6-8 for helpful discussion of important complications that I ignore here.

${ }^{22}$ The eliminativism mentioned here is a close cousin of the second kind of eliminativism mentioned in Braddon-Mitchell and Jackson 2007, 278-9. Their version applies to terms that fail to plays a role in predictive or explanatory science.

${ }^{23}$ I here ignore the nature of the possible functors: arbitrary combinations of conjunction, disjunction, and quantifiers appear acceptable, but negation does not: the property of being not natural is obviously not a natural property.

${ }^{24}$ Despite my example of tastiness, my characterization of the deflationary realist contrasts with Williams' discussion of realism (1985, Ch. 8), and Wright's discussion of judgment-dependence (1994). What makes a deflationary property deflationary in my sense is not that its existence or detection depends in some way on our distinctive capacities. It is that the carving of the world made by that property is not a metaphysically significant joint.

${ }^{25}$ This simplifies; I prefer a recursive account on which normative properties could count as natural if some normative properties get real definitions in terms of other properties (e.g. other normative properties), which in turn get real definitions in terms of other properties... where this chain of definitions bottoms out in only basic natural properties. Such a recursive picture of reduction would allow us to state a 'layered' reductive naturalist picture of reality. The statement of Reductive Naturalism should perhaps also include a clause about abundant normative properties: the real definition of each abundant normative property is a function of basic natural and category-neutral properties. This rules out (bizarre) views on which all elite normative properties are naturalistic, but some abundant normative properties are not.

${ }^{26}$ Another respect in which the narrow conception is stronger than the broad notion is that the broad definition of non-naturalism is compatible with the existence of some naturalistic normative properties. The narrow view, by contrast, insists that all normative properties are sui generis. If one liked one could easily instead distinguish pure non-naturalism from all of the various (and I take it metaphysically unattractive) mixed views on which, for example, some normative properties are reducible to natural properties, some are irreducibly naturalistic, and some are non-naturalistic.

${ }^{27}$ It should be granted that some philosophers take some version of Hume's dictum to be analytic, not substantive. (See Wilson 2010, §2 for discussion.) However, on the broad metaphysical picture that I have been proposing, Hume's dictum is a claim about the really possible relations between metaphysically real joints. Absent substantial metaphilosophical baggage, it is hard to see how such a claim could be analytic. If 
Hume's dictum is not a substantive metaphysical principle, then the non-naturalist ought to simply be able to introduce a richer vocabulary within which to state the view that she holds, and then the alleged analyticity will be otiose.

${ }^{28}$ For discussion of these two questions, see respectively Wilson 2010 and my 2012.

${ }^{29}$ See Boyd 1997, Blackburn 1993, and Schroeder 2009, respectively.

\section{Works Cited}

Adams, Robert. (1999) Finite and Infinite Goods. (Oxford: Oxford University Press).

Audi, Robert. (1997) Moral Knowledge and Ethical Character. Oxford: Oxford University Press.

Bennett, Karen. (2008) "Exclusion, Again.” Being Reduced. Eds. Jakob Hohwy, Jesper Kallestrup. (Oxford: Oxford University Press), 280-305.

Blackburn, Simon. (1993) Essays in Quasi-Realism. (Oxford: Oxford University Press).

Boyd, Richard. (1997) "How to be a Moral Realist." Moral Discourse and Practice. Eds. Stephen Darwall, Allan Gibbard, and Peter Railton. (New York: Oxford University Press), 105-136.

Braddon-Mitchell, David, and Frank Jackson. (2007). Philosophy of Mind and Cognition. $2^{\text {nd }}$ Ed. (Malden, MA: Blackwell).

Chalmers, David. (1996) The Conscious Mind. (Oxford: Oxford University Press). ---, and Frank Jackson. (2001) "Conceptual Analysis and Reductive Explanation." Philosophical Review 110: 315-61.

Dancy, Jonathan. (2006) "Nonnaturalism." Oxford Handbook of Ethical Theory. Ed. David Copp. (Oxford: Oxford University Press), 122-145.

Dreier, James. (1992) “The Supervenience Argument against Moral Realism.” Southern Journal of Philosophy 30.3 (1992): 13-38.

Dworkin, Ronald. (1996) “Objectivity and Truth: You'd Better Believe It.” Philosophy \& Public Affairs 25(2): 87-139.

Enoch, David. (2011) Taking Morality Seriously. (Oxford: Oxford University Press).

FitzPatrick, William. (2010) “Non-naturalist Ethical Realism.” New Waves in Metaethics. Ed. Michael S. Brady. (Houndmills: Palgrave Macmillan), 7-35.

Gibbard, Allan. (2003) Thinking how to Live. (Cambridge, MA: Harvard University Press). Harman, Gilbert. (1977) The Nature of Morality. (New York: Oxford UP).

Hawthorne, John. (2006) "Epistemicism and Semantic Plasticity" Metaphysical Essays. (Oxford: Oxford University Press), 185-210.

Huemer, Michael. (2005) Ethical Intuitionism. (New York: Palgrave Macmillan). Jackson, Frank. (1998) From Metaphysics to Ethics. (Oxford: Oxford University Press).

Kim, Jaegwon. (1993) Supervenience and Mind. (Cambridge, UK: Cambridge University Press).

---. (2008) "Reduction and Reductive Explanation: Is One Possible Without the Other?". Being Reduced. Jakob Hohwy and Jesper Kallestrup eds. (Oxford: Oxford University Press), 93-114.

---. (2011) "From Naturalism to Physicalism: Supervenience Redux." Proceedings of the American Philosophical Association 85(2): 109-134.

Kramer, Matthew. (2009) Moral Realism as a Moral Doctrine. (Oxford: Blackwell). 
Lewis, David. (1983) “New Work for a Theory of Universals.” Australasian Journal of

Philosophy 61(4): 343-377.

---. (1984) "Putnam's Paradox.” Australasian Journal of Philosophy 62(3): 221-236.

--- (1986) On the Plurality of Worlds. (Oxford: Blackwell).

Mackie, J. L. (1977) Ethics: Inventing Right and Wrong. (Harmondsworth: Penguin).

McPherson, Tristram. (2011) “Against Quietist Normative Realism.” Philosophical Studies 154 (2): 223-240.

---. (2012) "Ethical Non-Naturalism and the Metaphysics of Supervenience." Oxford Studies in Metaethics Vol. 7. Russ Shafer-Landau ed. (Oxford: Oxford University Press). 205-234.

Majors, Brad. (2007) “Moral Explanations.” Philosophy Compass 2(1): 1-15.

Miller, Alexander. (2003) An Introduction to Contemporary Metaethics. (Cambridge: Polity). Moore, G.E. (1903) Principia Ethica. (Cambridge: Cambridge University Press).

Nagel, Ernst. (1961) The Structure of Science. (New York: Harcourt Brace).

Oddie, Graham. (2005) Value, Reality, and Desire. (Oxford: Oxford University Press).

Parfit, Derek. (2011) On What Matters. Volume 2. (Oxford: Oxford University Press).

Railton, Peter. (1989) "Naturalism and Prescriptivity." Social Philosophy and Policy 7.1: 151174.

---. (1997) “Moral Realism.” Moral Discourse and Practice. Eds. Stephen Darwall, Allan

Gibbard, and Peter Railton. (New York: Oxford University Press), 137-163.

Rosen, Gideon. (2010) "Metaphysical Dependence: Grounding and Reduction.” Modality.

Bob Hale and Aviv Hoffman Eds. (Oxford: Oxford UP), 109-136.

Scanlon, Thomas. (1998) What We Owe to Each Other. (Cambridge, MA: Belknap).

---. (2003) "Metaphysics and Morals." Proceedings and Addresses of the American Philosophical

Association 77 (2): 7-22.

Schroeder, Mark. (2007) Slaves of the Passions. (Oxford: Clarendon).

--- (2009) "Hybrid Expressivism: Virtues and Vices." Ethics 119: 257-309.

---. (forthcoming) "What Matters About Metaethics?" Does Anything Really Matter? Responses

to Parfit. Peter Singer Ed. (Oxford: Oxford University Press).

Shafer-Landau, Russ. (2003) Moral Realism: A Defence. (Oxford: Clarendon).

---. And Terence Cuneo, Eds. 2007. Foundations of Ethics. (Oxford: Blackwell).

Sider, Theodore. (2012) Writing the Book of the World. (New York: Oxford University

Press).

Smith, Michael. (1994) The Moral Problem. (Oxford: Blackwell).

--- (2004) "Does the Evaluative Supervene on the Natural?" Ethics and the A Priori.

(Cambridge: Cambridge University Press), 208-233.

Stoljar, Daniel. (2010) Physicalism (Milton Park: Routledge).

Sturgeon, Nicholas. (1988) "Moral Explanations." Essays on Moral Realism Ed. Geoff Saye-

McCord. (Ithaca, NY: Cornell University Press). 229-255.

---. (2009) "Doubts about the Supervenience of the Evaluative." Oxford Studies in Metaethics

Vol. 4. Ed Russ Shafer-Landau. (Oxford: Oxford University Press), 53-92.

van Roojen, Mark. (1996) "Moral Functionalism and Moral Reductionism." The

Philosophical Quarterly 46.182: 77-81.

Wedgwood, Ralph. (2007) The Nature of Normativity. (Oxford: Oxford University Press).

Williams, Bernard. (1985) Ethics and the Limits of Philosophy. (Cambridge: Harvard UP). 
Wilson, Jessica. (2010) “What is Hume's Dictum, and Why Believe It?” Philosophy and Phenomenological Research 80.3: 595-637.

Wright, Crispin. (1992) Truth and Objectivity. (Cambridge: Harvard UP). 